\title{
Ethnic enclaves and segregation-self-employment and employment patterns among forced migrants
}

\author{
Johan Klaesson • Özge Öner
}

Accepted: 1 November 2019 / Published online: 20 January 2020

(C) The Author(s) 2020

\begin{abstract}
The relevance of residential segregation and ethnic enclaves for labor market sorting of immigrants has been investigated by a large body of literature. Previous literature presents competing arguments and mixed results for the effects of segregation and ethnic concentration on various labor market outcomes. The geographical size of the area at which segregation and/or ethnic concentration is measured, however, is left to empirical work to determine. We argue that ethnic concentration and segregation should not be used interchangeably, and more importantly, the geographical area at which they are measured relates directly to different mechanisms. We use a probabilistic approach to identify the likelihood that an immigrant is employed or a self-employed entrepreneur in the year 2005 with respect to residential segregation and ethnic concentration at the level of the neighborhood, municipality, and local labor market level jointly. We study three groups of
\end{abstract}

J. Klaesson $(\bowtie) \cdot$ Ö. Öner

Centre for Entrepreneurship and Spatial Economics, Jönköping International Business School, Jonkoping, Sweden

e-mail: johan.klaesson@ju.se

Ö. Öner

e-mail: oo263@cam.ac.uk

J. Klaesson · Ö. Öner

Research Institute of Industrial Economics (IFN), Stockholm, Sweden

Ö. Öner

Department of Land Economy, University of Cambridge, Cambridge, UK immigrants that accentuate the differences between forced and pulled migrants: (i) the first 15 member states of European Union (referred to as EU 15) and the Nordic countries, (ii) the Balkan countries, and (iii) countries in the Middle East. We find that ethnic enclaves, proxied by ethnic concentration at varying levels, indicate mixed results for the different immigrant groups we study, both for their employment and entrepreneurship probability, whereas residential segregation has a more uniformly distributed result where its relationship to any of the two labor market outcomes is almost always negative or insignificant.

Keywords Immigrant entrepreneurship - Ethnic enclaves · Segregation $\cdot$ Push entrepreneurship $\cdot$ Local labor market

JEL classifications $\mathrm{F} 22 \cdot \mathrm{O} 18 \cdot \mathrm{L} 26 \cdot \mathrm{R} 23$

\section{Introduction}

Migration to Europe is not a recent phenomenon. But the historically high rates at which many European countries have received refugees from parts of Middle East during the recent years has raised the concerns for the integration of immigrants dramatically. High unemployment among the minorities in the receiving countries manifests itself as one of the biggest challenges to overcome. There is a strong consensus both in academia and among policy makers that geographical sorting of immigrants, both between and within local labor 
markets, is crucial for the successful integration of immigrants into the society. There are two empirical regularities that are closely associated with the labor market outcome of the immigrants. Peers of a particular ethnic or cultural group collocate in close proximity to each other and residentially segregated from the natives. These two empirical regularities, which are often referred to as ethnic enclaves and segregation in the literature, have serious policy implications and are at the fore in the political discourse about immigration in many European countries.

Although the literature on ethnic concentration and residential segregation is extensive, there is no consensus about their effect on immigrants' labor market outcomes. Several competing and complementing mechanisms point to different outcomes. On the one hand, it is argued that the geographical concentration of ethnic groups may facilitate employment and entrepreneurship for immigrants through social network effects (e.g., Edin et al. 2003, Cutler et al. 2008, Patacchini and Zenou, 2012; Bayer et al., 2008). On the other hand, concentration of ethnic peers and separation from the natives may result in undesirable outcomes through "lock-in" effects, where immigrants remain at a certain distance from the natives and opportunities (Borjas, 2000).

The lack of consensus in the empirical literature on ethnic enclaves and segregation originates from the differences in measurements and research designs. In this paper, taking a step back from the existing literature, we aim at highlighting a few of these empirical issues. First, most of the previous studies focus on the relevance of ethnic enclaves and segregation using a single geographic level of aggregation, e.g., neighborhoods in a city. Second, segregation and ethnic enclaves, although highly correlated with one another, do not capture the same mechanisms. We argue that segregation and ethnic concentration operate differently (and at different scales) depending on the geographical aggregation in question. We also argue that the variation in the employment or entrepreneurship outcome that originates from the measurement of ethnic concentration, residential segregation, and from the choice of geographical aggregation is not random. For example, while high segregation in a neighborhood may indicate separation from the natives living in the same city, ethnic concentration in the neighborhood may imply access to a large ethnic social network. In an analogous way, while municipality-wide ethnic concentration entails a large ethnic market for a potential ethnic business, segregation in a municipality (with respect to the larger region) may imply disadvantageous labor market conditions. By way of this paper, we contribute to the literature by investigating the relevance of such geographical layering for employment and entrepreneurship prospects of immigrants using Sweden as a case, and we display how results systematically differ between ethnic concentration and segregation at various geographical levels.

\subsection{Motivation and contribution}

The empirical framework utilizes a probabilistic approach to identify the likelihood that an immigrant is employed or a self-employed entrepreneur in the year 2005 with respect to segregation and ethnic concentration at the level of the neighborhood, the municipality, and at the local labor market level. We study three groups of immigrants that accentuate the differences between Swedish minority labor markets: immigrants from (i) the first 15 member states of European Union (referred to as EU 15) and the other Nordic countries, (ii) the Balkan countries, and (iii) countries in the Middle East. Different from the North American context, where a clear majority of the immigration arguably is opportunity driven, the Swedish context allows us to understand the relationship between segregation and labor market outcomes for the forced migrants, since the majority of the migration from the Balkan countries and the Middle East can be labeled forced migration (Dahlberg et al., 2016). The category native Swedes serves as a benchmark, and the immigrants from the EU 15 and Nordic countries represent opportunity driven migration or pulled migration. The selection of the years covered by the study is based on two distinct peaks in the migration flows to Sweden, both of which can be thought of as exogenous shocks in the migration patterns (see Fig. 1). The first peak occurs in the early 1990s following the turmoil in the former Yugoslavia (Yugoslav wars); the second peak is observed around 2006 following the Iraq war. Our goal is to identify the probability that individual immigrants are employed or self-employed respectively related to geographical ethnic segregation and ethnic concentration at various levels of spatial aggregation. We argue that the year 2005 is sufficiently long after the Balkan migration wave, allowing segregation and concentration effects to manifest themselves, and right before the Iraqi war, which may have yielded a significant and immediate alteration of the degree of segregation or concentration 
Fig. 1 Immigrants from three regions by entry year 1990-2015, Data source: Statistics Sweden, Figure: by authors

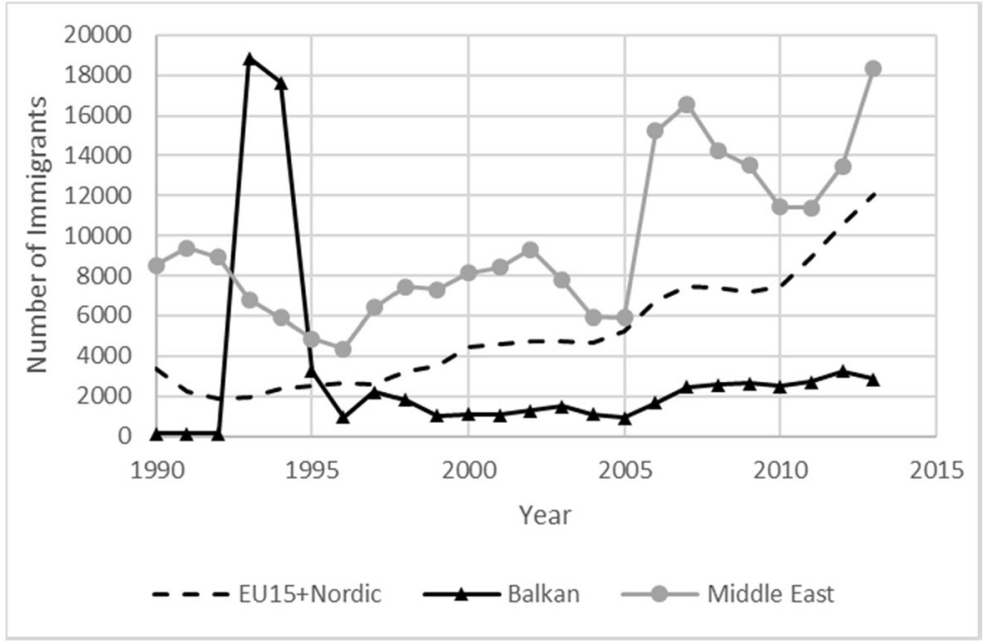

in the neighborhoods we study. Our goal is not to isolate sorting and selection effects, but rather to capture an overall pattern for how the likelihood of employment or self-employment relates to segregation and ethnic concentration. Therefore, rather than capitalizing on a shock - like the one in early 1990s with the Balkan immigration-we present an empirical framework that is replicable for different waves of migration and migrant groups.

Our first empirical point is that ethnic concentration and residential segregation are two distinctly different phenomena. While ethnic concentration captures the share of the total population within a geographical area that corresponds to an immigrant group, a residential segregation measure (e.g., dissimilarity index) captures how the distribution of the population in an area differs from a larger area it is part of. The ethnic concentration can be high in an area with low levels of segregation and vice versa. We test our labor market outcome variables, employment and entrepreneurship, both against the ethnic concentration and the residential segregation to show that the results indeed contrast.

The second empirical point we make is related to geography itself. We argue that geography should be considered in an empirical framework with the two following questions in mind: (i) what level of geography and (ii) which geography. Regarding the level of geography, we argue that the geographical aggregation at which ethnic concentration and segregation is measured not only displays different empirical regularities but also signals different mechanisms. For example, if we are to capture residential segregation at the neighborhood level, it tells us how different a certain neighborhood looks compared to the city it belongs. But it can be the case that the city itself is segregated compared to the greater local labor market area it is part of. These two then would signal rather different mechanisms for the labor market outcomes of immigrants. While segregation at the neighborhood level captures mechanisms related to social exclusion, segregation at the city level may indicate a specific landscape for the local labor market. In fact, our analysis indicates that careful consideration of the segregation measure and the geographical level may provide information on different mechanisms through which immigrants realize labor market opportunities through employment and entrepreneurship. The same logic applies to ethnic concentration. For example, while ethnic concentration at the neighborhood level may imply strong network effects an immigrant can capitalize on (or suffer from), ethnic concentration at the city level may relate to basic supply and demand mechanisms in the market. In broad strokes, we find that ethnic concentration in the neighborhood is not associated with desirable outcomes, but at the city level, they relate to a higher probability of entrepreneurship and employment. Segregation, on the other hand, almost always has a negative association with the outcomes we study regardless of the aggregation.

The second question that needs careful consideration is which geography. There is often an implicit assumption that segregation is an urban phenomenon, as we have historically seen that ethnic enclaves are formed in parts of urban areas in the western world. That is one 
reason why we notice that most of the segregation studies is carried out in neighborhoods in one or a few metropolitan areas in the studied countries. However, in many European countries (Sweden in particular), the newly arrived refugees are placed in peripheral local labor markets with high unemployment rates and depopulation. This policy is necessitated and driven by a lack of housing opportunities in the larger urban areas with more and more diverse opportunities. Consequently, segregation and ethnic concentration are no longer necessarily an urban/metropolitan phenomenon only. This kind of geographical sorting across local labor markets across the country suggests that a selection of a limited number of metropolitan areas may generate biased results. In our empirical analysis, we use all municipalities and regional markets in Sweden rather than only the more urban/metropolitan areas. The only other study - to our knowledge - that considers the relevance of residential segregation for labor market outcomes at the neighborhood and city levels separately study only the largest metropolitan areas in Sweden (see Hedberg and Tammaru, 2013).

Our results suggest a significant variation across the immigrant groups we study. The pulled migrants have a distinctively different pattern than the forced migrants. Also, with a higher degree of heterogeneity among the Middle Eastern immigrants (compared to the Balkan immigrants), we find that the results between these two groups differ. In broad strokes, we see that segregation is associated with negative labor market outcomes (both employment and entrepreneurship) when there is a statistically significant association. We find mixed results for ethnic concentration, and the relevance of ethnic concentration is heavily dependent on the geographical resolution.

\section{Segregation, ethnic concentration, and immigrants' labor market outcomes}

It is a well-known and almost uniform pattern that not only immigrants in many countries are residentially segregated as a group, but also different ethnic groups tend to be geographically sorted into different places (Borjas, 1995, 2000). Such spatial sorting may be voluntary, where immigrants favor areas with a high share of ethnic/cultural peers with whom they share a common language and/or cultural background. But residential separation can also be the result of institutional mechanisms and path dependency. Institutions may work both at the national and at the sub-national level to alter the geographical distribution of a particular subpopulation and sometimes without an explicit intention to do so. For example, zoning and planning regulations that dictate land use in many Western countries may make certain parts of the housing market unaffordable for a certain income group. Similarly, rent control may result in low rates of churn, which may hinder availability of affordable apartment units in central locations. Central placement of newly arrived immigrants (mostly refugees) into certain parts of the country may also initiate path dependency. As a result, a significant minority cluster may grow and persist over time at a given location. These factors are not mutually exclusive, and they are not universal in the way they manifest themselves. It can certainly be a combination of several mechanisms that operate simultaneously, which lead to the formation of ethnic enclaves and residential segregation. Historically, segregation and neighborhood diasporas characterized many cities of the western world. Abstracting from the formation of such areas, we investigate how the nature of segregation and ethnic concentration relate to the labor market outcome of immigrants. How is living in ethnic enclave or segregated area associated with the labor market outcomes for immigrants? In this section, we list some of the common arguments repeated in the previous literature related to immigrant's entrepreneurship and employment outcomes in relation to geography of immigrants.

\subsection{Entrepreneurship (self-employment)}

The literature on ethnic and immigrant entrepreneurship is vast. Most of the previous research highlights the importance of self-employment as a tool for transitioning from unemployment to employment for immigrants with limited opportunities in the labor market. The simple argument is that the significant labor market gap between natives and immigrants in many countries $^{1}$ can be mitigated by self-employment (Clark and Drinkwater 2000). A combination of lack of skills or inability to validate existing skills, lack of knowledge of labor markets and institutions (Bates 2011), potential labor market discrimination, ${ }^{2}$ and limited supply of

\footnotetext{
${ }^{1}$ See also Nannestad (2009), Jean et al. (2010), and OECD (2006)

${ }^{2}$ See, e.g., Arai and Skogman Thourise (2009) and Carlsson and Rooth (2007)
} 
well-paying jobs with low entry barriers lead to acquiring low-income/low-status jobs which further incentivizes immigrants to consider self-employment as a viable option. $^{3}$

As the entrepreneurial intentions are built on different expectations, we see a significant variation between the native and immigrant entrepreneurs, as well as between different types of immigrants. For example, Levie (2007) shows large variation in propensity to engage in entrepreneurship across individuals with different migrant status in the UK (i.e., those who migrate across the regions of the UK compared to immigrants from outside the UK). Large and persistent variation in entrepreneurial engagement is not exclusive to the binary natives/immigrant divide. In fact, a number of papers discuss that institutional, cultural, and economic milieu from which immigrants come dictate their entrepreneurial engagement in the receiving country significantly (Lassmann and Busch, 2015; Hout and Rosen, 2000; Walstad and Kourilsky, 1998; Clark and Drinkwater, 2000).

Entrepreneurial outcome is also dependent on individuals' characteristics, which attracted vast attention in the entrepreneurship literature. ${ }^{4}$ For example, in their sequential analysis of immigrant entrepreneurship in Luxembourg, Peroni et al. (2016) find that first generation immigrants, especially those with high human capital, have a higher propensity to start a business than non-immigrants. A similar variation is also evident between female and male immigrants, although it is underemphasized in the literature (Collins and Low, 2010).

Central to our study, the immediate environment immigrants live in directly or indirectly relates to their entrepreneurial engagement, signaling an "enclave effect." Individuals that share common ethnicity, culture, language, and/or religion tend to socially interact with one another to a greater extent. By the way of already established ethnic peers in the labor market, aka the role models, an immigrant can access to valuable information on self-employment. If not benefiting from the social interaction itself, a certain degree of ethnic concentration may also allow the immigrant to tap on the basic supply-demand mechanisms in the market, which would make it possible for her to run an ethnic/cultural

\footnotetext{
$\overline{3}$ However, Lofstrom and Lofstrom (2014) finds that no strong evidence that self-employment can be an effective tool to have upward economic mobility for low-skilled immigrants.

${ }^{4}$ See Parker (2009) for an extensive discussion.
}

business that caters ethnic/cultural consumers or find a particular type of employee with the cultural knowledge when needed (Lee, 2000; Andersson, 2017, Andersson et al. 2017).

The power of social capital in small and tightly knit communities may enable individuals, firms, and communities of various kinds to get involved in cooperative and high-trust networks. This aspect of social capital is especially important for an immigrants' ability to start a business, where the ethnic network can potentially reduce transaction costs, mitigate regional, and urbanrural disparities where lack of material resources is substituted with more immaterial and value-based cultural assets (Knack and Keefer, 1997).

However, the empirical evidence for the benefits of living in an enclave is mixed. If the ethnically concentrated area is residentially separated from the natives and have a relatively deprived nature, rather than fostering entrepreneurial engagement, it may depress selfemployment opportunities (see Clark and Drinkwater 2000, 2002, 2010). In a critical review, Kloosterman and Rath (2001) argue that the neo-classical models for entrepreneurship neglects the demand side and the matching processes in the market. Similar to our empirical motivation to use different layers of geography, Kloosterman and Rath also argues that a "three-level approach" should be used as a framework to analyze the opportunities in the market where national, regional/ urban, and the local (or neighborhood) spatial levels are considered separately. The intra-urban spatial structure of consumer markets can enable the immigrants to offer products that are not offered by the native population (Kloosterman and Rath, 2001).

\subsection{Employment}

Segregation and ethnic enclaves in relation to labor market sorting of immigrants are studied extensively. Edin et al. (2003) use a Swedish refugee placement policy where government assigned refugee immigrants to an initial municipality of residence between 1985 and 1994. The authors find that living in enclaves improves the labor market outcomes for less skilled immigrants, and the members of high-income ethnic groups are found to gain more from living in an enclave compared to people that belong to low-income ethnic groups (Edin et al., 2003). Similarly, Cutler et al. (2008) find in their paper for the first-generation immigrants to the USA that segregation can be beneficial. In the US context, 
Beaman (2012) examines the dynamic implications of social networks for the labor market outcomes of refugees. Beaman finds that an increase in network size has a heterogeneous effect, where a one standard deviation increase the number of network members that arrive 1 year prior to the newly arrived refugee lowers his probability of being employed by $4.8 \%$ points. For the Canadian labor market, Warman (2007) studies the impact of living in an ethnic enclave on earnings growth of immigrants. The author finds an overall negative impact of enclaves on weekly earnings growth of immigrants.

In estimating the effects of segregation, one obvious problem is the potential endogeneity. It is difficult to distinguish what kind of effect comes from peer effects in a residential area (Manski, 1993). The impact of ethnic enclaves and segregation can be overestimated due to a common factor effecting both the labor market outcomes of its residents and the segregation itself (e.g., culture or institutions). Another issue is what kind of benchmark to use to consider the labor market outcomes related to segregation. A traditional approach is to look at the natives in a country when we are trying to understand the employment or entrepreneurship conditions for minorities. That, however, may be problematic in the context of segregation since the mechanisms through which the natives sort themselves into an area may differ drastically from those that define the residential separation of minorities (Warman, 2007). For that reason, it is plausible to look into labor migrants with relatively related cultural background to natives as a benchmark in addition to the natives. We follow this approach in our empirical application.

There is, at times, a dark side to tightly knit immigrant networks. Borjas (2000) argues that an ethnic enclave can become "an economic stranglehold" by excluding immigrants from outside alternatives, but also by making it challenging for them to acquire the skills that are necessary for labor market integration (such as language proficiency) (Borjas, 2000, pg. 93).

Relating to the dark side of ethnic enclaves and segregation, Borjas (2000) finds that low-skilled workers have more difficulty in realizing opportunities in the labor market outside of their enclave, this shortcoming they substitute with the possibilities within the ethnic enclaves in their segregated neighborhoods. The skills of the immigrant in terms of education is an important factor in determining the labor market outcome of segregation, and therefore needs to be controlled for. For high-skilled immigrants, both Edin et al. (2003) and Borjas (2000) find no significant impact from residing in a segregated area. In an earlier study, Borjas (1998) analyzes the link between ethnicity and the location choice of immigrants concerning the choice to reside in a segregated neighborhood. The study provides a theoretical and empirical analysis on the determinants of the ethnic residential segregation. He finds dispersion within and across ethnic groups in the probability that a person does live in ethnically segregated neighborhoods. This finding is important because it constitutes a motivation for taking different ethnic groups into account separately, both for the formation of segregation and the consequences of it. Borjas (1998) also finds that factors such as income, parental skills, and ethnic capital determine the ethnic mix of the neighborhoods where persons choose to live. Greater income inequality between the groups is found to generate further segregation.

\section{Layers of segregation: neighborhood, city, and region}

There is a recent and growing literature on non-market interactions that suggests the effects of social interaction are highly localized in space (Arzaghi and Henderson, 2008; Rosenthal and Strange, 2008; Larsson 2014a; Andersson et al. 2016b; Andersson and Larsson, 2014). Two competing arguments about segregation and its potential influence on labor market outcomes suggest that it can be good or bad to live in an ethnically separated area. The geographical size of such an area, however, is much left to empirical work to determine. We argue that the size of the residential area is crucial in understanding the mechanisms through which ethnic separation may be good or bad for the employment or entrepreneurial outcomes for immigrants. This idea is motivated by a large body of literature that is rooted in urban and regional economics. The importance of spillover effects originating from individuals' interactions is not a recent idea. Social interactions are argued to partly determine the spatial distribution of economic activity and people too (Glaeser et al., 2000). Some of the empirical work favors the idea that there is a clear relationship between social networks and employment (Andersson et al. 2009; Bayer et al. 2008; Topa, 2001). In a parallel literature, it is argued that benefits arise due to "weak links" in a network (Granovetter, 1973, 1995). Granovetter's argument is that it is not the strong link between the individuals of a tight 
network that deliver desirable outcomes for, e.g., labor market outcomes. Rather, it is the weak links that are important. They constitute a large pool of individuals with so-called bridging ties. It is the friend of your friend that finds you your first job. For the immigrant population, however, there is not an abundance of such weak links. So, they rely on their small but strong network more than the natives do. For example, Zenou (2007) finds that individuals who live in segregated areas rely heavily on this type of strong ties for information related to the labor market. These ties are found to predominately operate at the neighborhood level. What will be the effect if such a network is mainly populated by unemployed individuals? Then, these strong ties, combined with a lack of weaker bridging ties, will lead to a lower chance of finding a job or acquiring the needed information for entrepreneurial ventures (c.f. Hensvik and Nordström Skans, 2013).

Social interaction has a clear spatial dimension. Certain types of non-market interactions mainly take place within a certain geographical level. High-trust interactions facilitated by similarities between the individuals in a network are argued to reduce transaction costs for the individuals. This mitigates challenges with job search or search for information needed to start a business. This sort of information is then spatially sticky and manifests itself at small scales of geography such as neighborhoods. Knowledge spillovers, for example, are argued to take place at very small geographical aggregations (Rosenthal and Strange, 2008; Arzaghi and Henderson, 2008; Larsson, 2014b). At a larger scale of geography, it is the bridging ties across individuals with different skill sets that are important. Issues related to labor market pooling and matching processes require a greater market area to be sufficiently dynamic and diverse.

While a large share of immigrants, or segregation, can be a good thing for an immigrant at the neighborhood level, this type of spatial separation at the city level may bring opposite results. First, it may be a signal of the overall market conditions. For immigrants to be concentrated at the city level, the housing market probably must comprise enough affordable and vacant homes. Such availability in itself implies that the location is not a preferred one by the high-income natives. In this case, it indicates a negative selection. Second, if the city or region is populated by a relatively large share of immigrants, that may mean that there is a lack of depth and breadth in the demand profile for the potential services and goods immigrant entrepreneurs might produce.
Last, but not least, a higher immigrant concentration or residential separation at the city level relates directly to competition for a limited number of jobs in the local labor market. Through our empirical exercise, we investigate whether the direction of the change in probability for employment or (push) entrepreneurship changes when we investigate the neighborhood and the city simultaneously. In doing so, we do not only look at the ethnic concentration, but we also use a dissimilarity index that indicates relative residential separation in a neighborhood or municipality with respect to a greater geographical area.

Hedberg and Tammaru (2013) use a rather similar approach to our analysis and analyze the "neighborhood effects" and "city effects" for the labor market outcomes of new immigrants. Unlike most studies, their focus is not only on spatial attributes on immigrant labor market careers within a city (neighborhoods) but also on the effect between cities. They conduct a longitudinal study on the entry onto the labor market between 1994 and 2002 of the 1993 immigrant cohort in Stockholm and Malmö. They find that both the neighborhood and city context matter for newly arrived immigrants entering the labor market. They find that neighborhood effects diminish over time; city effects are robust throughout the whole period. Disadvantages of living in "distressed" neighborhoods are less important in large and globally competitive cities (as in living in a distressed neighborhood in Stockholm raises employment chances compared with residing in a distressed neighborhood in Malmö.). They also arrive to the point that constitutes our motivation: neighborhood effects cannot be understood independently of city effects.

Built on the aforementioned research, we pin down the mechanisms we consider for the two labor market outcomes, entrepreneurship and employment, in relation to the geographical aggregation. In Table 1, we list a number of competing and complementing arguments for the relevance of ethnic concentration and segregation at three geographical aggregations: neighborhood, city, and region (aka local labor market).

\section{Immigration to Sweden during the last 25 years}

Sweden, like many other European countries, has been an attractive location for immigrants from around the world. During the 1950s and 1960s, the recruitment of migrant workers was an important determinant of 
Table 1 Mechanism and what to expect?

Ethnic concentration (i.e., enclave)

1. Neighborhood: An ethnic concentration at the neighborhood level implies an opportunity to build stronger social ties, have better knowledge dissemination among peers, potential job referrals, entrepreneurial role models, etc. These may be useful for employment as well as entrepreneurship outcome. However, an excessive concentration of ethnic peers may also signal social exclusion and larger distance to the natives.

2. Municipality: All the above applies to some extent also at the municipality level, but the effects are reduced by aggregation as the distance between the peers is larger (attenuation). But more importantly, municipal-level ethnic concentration should relate to the supply and demand mechanisms to a larger extent. A higher ethnic concentration at the municipal market then may mean that there is sufficient demand for a potential ethnic entrepreneur. But the results for employment may be mixed. Because on the one hand, ethnic entrepreneurs will want to hire ethnic labor, but on the other hand there will be more competition for any given individual.

3. Region: A higher concentration at the regional level should relate -to a large extent- to the labor market area for job search and degree at which they may commute. For the entrepreneurs, it relates to labor supply and extent of demand. If the labor market area is the relevant search area for the immigrants, then a higher concentration of ethnic peers should imply higher competition for employment, but a larger labor supply and demand for an entrepreneur. If the area is too large to be relevant for either of the two outcomes, then we should not see any significant results.
Residential segregation

1. Neighborhood vs. municipality: While a high segregation at the neighborhood level may entail some of the benefits we listed under the ethnic concentration (e.g., social ties, network effects), it also may mean that due to being significantly different than the other neighborhoods in the municipality, it may mean social separation and exclusion. If the distribution of ethnicity in a neighborhood is significantly different compared to the municipality, it may imply a limitation for positive between-neighborhood effects.

2. Neighborhood vs. region: A high level of segregation at the neighborhood against the region, or in other words local labor market, implies that the concentration of ethnic peers at that neighborhood is significantly different than it is in the region.

3. Municipality vs. region: A high segregation at the municipal level implies that the distribution of the population in a given municipality is significantly different than the region (local labor market) it is hosted in. Such a pattern may emerge simply due to residential sorting, if the municipality is predominantly residential from which individuals commute for work elsewhere in the region. While it may be useful for entrepreneurship outcomes of individuals (for example for running an ethnic business), it also signals that immigrants are separated from the rest of the labor market, which potentially increases frictions related to the local labor market where obtaining information on possible jobs is scarce, and opportunities to learn "know-how" for starting a business and/or applying for jobs are limited. immigration flows. Because of a trade agreement signed in 1952 between the Nordic countries, a common labor market was formed, which enabled free movement across borders within Scandinavia. Especially, migration from Finland to Sweden undoubtedly is one of the essential mechanisms that enabled the creation of the tax base required for the expansion of the large public sector now a characteristic of Scandinavia. This continued until 1967 at which point the labor market became saturated, and Sweden introduced new immigration controls. It was not only Nordic labor migrants but also labor market migrants from Turkey too that came to Sweden during this period.

Since the early 1970s, immigration to Sweden has been mostly due to refugee migration. In the last 25 years, the former Republic of Yugoslavia has been a large source of migrants due to the Yugoslav Wars in the 1990s. Migrants originating from countries in the Middle East have been prominent too. If we look at Fig. 1 below, we see that around 1992-1993, there is a peak representing the individuals that migrated to Sweden from the Balkan countries. An increasing trend following Sweden's entry as a member of the European Union can also be observed starting from around 1994. The type of peak we observe in early 1990s following the Yugoslavian war can also be seen for 2006 for the Middle Eastern refugees. The difference between the two trends is that for the Middle East refugee flow, the level of migration does not bounce back to where it was prior to 2006 as it did for Balkan refugees.

Residential separation in Sweden can mainly be observed in the so called 'Million Homes Program' neighborhoods. These neighborhoods were the results of a government policy directed towards housing shortages and large-scale housing complexes were constructed between 1965 and 1974. The program aimed at building one million new dwellings during a 10 -year period to provide affordable housing units and to deal with the housing shortage simultaneously during this period. Both policy targets were severe problems at the time, especially for recently arrived immigrants. The program proceeded as planned, and the targeted number of dwellings was built in the period. But the very fast expansion of these areas led them to be very different in nature from areas that evolve over time. They were situated far outside of the urban core. This and other factors caused a social separation and segregation of their inhabitants. 


\section{Empirical model and data}

In this section, we present the main empirical model used to understand the relationship between the geographical distribution of the selected ethnic/ cultural immigrant groups and labor market outcomes of individuals belonging to the same groups. The data is a full population registry micro-data, and it is maintained by Statistics Sweden. It contains information at the individual, establishment, and firm levels. We have a number of individual characteristics we can identify in the data, as well as a region of origin that consists of a number of countries. Although there are a large number of countries that are listed under Middle East, a vast majority of the individuals that we have in that group are from a few countries such as Iraq, Iran, and Turkey. The three groups of immigrants we analyze are the groups introduced in the former section: EU 15 + Nordic, Balkan, and the Middle East. The labor market outcomes we are interested in are employment and entrepreneurship. We aim to disentangle the relationship between several individual and regional level variables and the probability that an individual is employed. In an identical framework, we investigate the probability that an individual is an entrepreneur. Here, we equate entrepreneurship with business ownership.

Our main variables of interest describe variations in the geographic distribution of different ethnic groups. In the actual analysis, we differentiate between four distinct groups. The first group, mainly used as a benchmark, is labeled natives. Natives are defined as people that are born in Sweden. As homogenous as the group is, it includes individuals that may be second-generation immigrants. The second group is people that have immigrated from the core of the EU (EU 15) plus immigrants from the Nordic countries and Switzerland. The immigration numbers of this group have had a steady increase since Sweden became a member of the EU in 1995. Almost all individuals represent labor migration in this group. We believe it is interesting to use this group as a comparison and benchmark since these immigrants are largely opportunity driven or in other words pull migrants. The third group consists of immigrants that originate from the Balkans. The fourth and last group consists of people that have migrated to Sweden from the Middle East. ${ }^{5}$ Although we do not have an individual refugee identifier, from the national figures, we know that a clear majority of both groups consist of forced migrants that arrived in Sweden by way of asylum rights. Both the Balkan immigrants and the immigrants from the Middle East are, therefore, considered to be push migrants that arrived Sweden through forced migration.

As discussed in the previous section, there is a peak in the migrant flow from the Balkans following the Yugoslavian war in early 1990s, and a similar peak can be observed in 2006 following the Iraqi war (as is seen in Fig. 1). Forced migrants from parts of the Middle East, however, have been rather steady until 2006. In our identification scheme, the intention to study the year 2005 is selected for two reasons: (i) it is arguably sufficiently long after the Balkan migration wave, allowing segregation and ethnic network effects to manifest themselves in individuals' labor market outcomes, (ii) and right before the Iraqi war and the peak of Middle Eastern migrants in 2006, which may have potentially yielded the reorganization of already segregated neighborhoods. This year presents us with a good opportunity to investigate segregation-labor market relationship in a cross-sectional set up.

To determine the geographical distribution of these ethnic groups, we use two measures. The first measure is just the share of people in an area that belong to each of the groups. We call this ethnic concentration. This way of looking at the geographical distribution of the immigrants allows us to observe the actual ethnic enclave effects in a neighborhood or in the city. The type of network effects we should observe in this measure is of the tight nature, where we should see an abundance of bonding social capital between its members. The second measure is a measure of segregation that is rather standard in the segregation literature. We use a dissimilarity index, which allows us to tell how dissimilar an area is compared to a greater area which it is a part of. The reason to use these two different measures is that for an immigrant, being in a segregated area does not necessarily entail an available ethnic enclave.

\footnotetext{
5 The three country groups consist of the following countries: EU $15+$ Nordic (Belgium, France, Greece, Ireland, Italy, Luxembourg, Netherlands, Portugal, Switzerland, Spain, Britain, Germany, Austria, Finland, Norway, Denmark, Iceland), Balkan (Albania, Kosovo, BosniaHerzegovina, Macedonia, Montenegro, Serbia), and Middle East (Bahrain, Egypt, United Arab Emirates, Iraq, Iran, Israel, Yemen, Jordan, Kuwait, Lebanon, Oman, Qatar, Saudi Arabia, Syria, Turkey)
} 
One of the novelties of our empirical analysis is that we use three different spatial units, one nested within the other. The finest spatial level we use for identification of the neighborhood is called "SAMS areas,", and there are about 9200 such areas in Sweden. The next spatial level we employ is the "Municipality," representing a city area in which the SAMS areas are contained in. In Sweden there are 290 municipalities. Municipalities are the smallest areas that have some degree of self-governance and its own formal institutions. Municipalities have taxation rights and handle large parts of social welfare, elderly care, and the school system at the first and secondary levels. The third and largest geographical level we use is the "Labor Market Areas," representing the region. Labor market areas are made up of municipalities that are grouped together based on commuting patterns. There are 72 such labor market areas in Sweden. These three geographical levels are related so that a number (on occasion only one) of municipalities make up a labor market area and a number of SAMS areas make up a municipality. Thus, the borders are aligning. No labor market area border crosses a municipality border, and no municipality border crosses a SAMS area border.

In order to measure the impact of differing settlement pattern between the four ethnic groups of people, we use two measures. The first is just the share of the group in the relevant area of the entire population. We use this as an indicator of ethnic concentration.

$S_{g, r}=\frac{P_{g, r}}{P_{r}}$

$P_{g, r}$ is the population of ethnic group $g$ in area $r$, and $P_{r}$ is total population in the area. $S_{g, r}$ is the share of group $g$ in area $r$.

The second measure is a segregation measure in the form of a dissimilarity index.

$D_{g, r}=100 \cdot\left(\frac{P_{g, r}}{P_{g}}-\frac{N_{r}}{N}\right)$

$P_{g, r}$ is the population of ethnic group $g$ in area $r$, and $P_{g}$ is population of ethnic group in the larger area of which $r$ is a part. $N_{r}$ is the native population in area $r$, and $N$ is native population in the larger area of which $r$ is a part. $D_{g, r}$ is the dissimilarity index.

We estimate logit models ${ }^{7}$ where the dependent variable in the first set of estimations indicates whether an

\footnotetext{
${ }^{6}$ SAMS stands for Small Areas for Market Statistics.

${ }^{7}$ Using STATA.
}

individual is employed or not. In the second set of estimations, the dependent variable indicates if an individual is an entrepreneur or not. The independent variables can basically be divided into individual level variables and regional level variables. As mentioned above, we use three different levels in the regional specifications: the SAMS area, the municipality, and the labor market areas. ${ }^{8}$ Our two empirical models can be represented by the following equations:

$$
\begin{aligned}
& \operatorname{Pr}\left(E_{i, t} \mid \mathbf{X}\right)=1 /\left(1+\exp \left[-\left(X^{\prime} \Gamma\right)\right]\right) \\
& X^{\prime} \Gamma=\alpha+\beta_{1} S_{n}+\beta_{2} S_{c}+\beta_{3} S_{r}+I_{i}^{\prime} \beta_{4}+Z_{j}^{\prime} \beta_{5} \\
& +\varepsilon_{i} \\
& X^{\prime} \Gamma=\alpha+\beta_{1} D_{n c}+\beta_{2} D_{n r}+\beta_{3} D_{c r}+I_{j}^{\prime} \beta_{4} \\
& +Z_{j}^{\prime} \beta_{5}+\varepsilon_{i}
\end{aligned}
$$

$E_{i, t}$ is a binary outcome variable indicating whether an immigrant is (i) employed or not, or (ii) an entrepreneur or not, in the year 2005. In the first specification, $S_{n}, S_{c}$, and $S_{r}$ denote the ethnic enclave in neighborhood, city, and the region respectively. In the second specification, $D_{n c}, D_{n r}$, and $D_{c r}$ denote the dissimilarity indices calculated for measuring segregation in order (i) in the neighborhood with respect to the city $(n c)$, (ii) in the neighborhood with respect to the region $(n r)$, (iii) and finally in the city with respect to the region $(c r) . I_{i}^{\prime}$ is a vector of variables at the individual level controlling for the observable characteristics of the immigrants in our analysis, and $Z_{j}^{\prime}$ is a vector of geographical variables that are used in the probability estimations. So in total we run four models for each immigrant group. The four specifications are made up of two different dependent variables (probability of employment and entrepreneurship respectively) and two measures of ethnic clustering (concentration and segregation respectively). In Table 2, we present all the variables that we use in our analysis.

Table 3 presents averages for all variables and for all four ethnic groups. Further descriptive statistics are found in the Appendix Table 8. In Table 3, we observe

\footnotetext{
${ }^{8}$ The fact that we use three geographical levels plus the individual level calls for a multilevel modeling technique. We address this issue
} below in Sect. 6. 
Table 2 List of variables used in the analysis

\begin{tabular}{|c|c|}
\hline Variable & Definition \\
\hline \multicolumn{2}{|l|}{ Dependent variables } \\
\hline Employed & $\begin{array}{l}\text { Dummy }=1 \text { if individual is employed. } \\
\text { The first dependent variable. }\end{array}$ \\
\hline Entrepreneur & $\begin{array}{l}\text { Dummy }=1 \text { if individual is a business owner. } \\
\text { The second dependent variable }\end{array}$ \\
\hline \multicolumn{2}{|l|}{ Individual variables } \\
\hline Age & Age of the individual \\
\hline Male & Dummy $=1$ if individual is male \\
\hline Education & Duration of education in years \\
\hline Time in Sweden & Number of years since immigration \\
\hline \multicolumn{2}{|l|}{ Spatial variables } \\
\hline Neighborhood size & Population in SAMS area \\
\hline Municipality size & Population in municipality \\
\hline Local labor market size & Population in labor market area \\
\hline Employment rate in the local labor market & Share of people in working age that have a job \\
\hline \multicolumn{2}{|l|}{ Ethnic concentration } \\
\hline Share of ethnic group in neighborhood & $\begin{array}{l}\text { Share of the population in the SAMS area } \\
\text { that belong to the ethnic group }\end{array}$ \\
\hline Share of ethnic group in municipality & $\begin{array}{l}\text { Share of the population in the municipality that } \\
\text { belong to the ethnic group }\end{array}$ \\
\hline Share of ethnic group in local labor market & $\begin{array}{l}\text { Share of the population in the local labor market } \\
\text { that belong to the ethnic group }\end{array}$ \\
\hline \multicolumn{2}{|l|}{ Segregation (dissimilarity index) } \\
\hline Segregation 1 (neighborhood vs. municipality) & $\begin{array}{l}\text { Dissimilarity index 1: percentage difference between } \\
\text { neighborhood share of municipality ethnic and native population }\end{array}$ \\
\hline Segregation 2 (neighborhood vs. local labor market) & $\begin{array}{l}\text { Dissimilarity index 2: percentage difference between } \\
\text { neighborhood share of labor market area ethnic and native population }\end{array}$ \\
\hline Segregation 3 (municipality vs. local labor market) & $\begin{array}{l}\text { Dissimilarity index } 3 \text { : percentage difference between } \\
\text { municipality share of labor market area ethnic and native population }\end{array}$ \\
\hline
\end{tabular}

some interesting differences between the different immigrant groups we have in the analysis. Starting with the two dependent variables: employment and entrepreneurship. Eighty percent of the natives are employed, $70 \%$ of the Balkans, $64 \%$ of the immigrants from EU 15 or the Nordic countries while only $48 \%$ of the immigrants from the Middle East have a job. This means that at the aggregate level there are great differences between the groups. Looking at entrepreneurship, we observe differences too. The outlier here is the immigrant group from the Balkans; only $2 \%$ are entrepreneurs. At the other end of the spectrum, we have the group from the Middle East of which 9\% are entrepreneurs. This figure is higher than that of the native group.

When it comes to age, the average is a couple of years below or above 40 . The exception is the immigrants from EU 15 and Nordic countries that are older on average. Education levels are about the same. Average time in Sweden since immigration is the longest for people originating from the EU 15 or the Nordic countries; for the Balkan and Middle East origins, it is less than half at about 10 years.

Regarding the population sizes of the different areal units, one interesting observation is that people from the Middle East seem to locate in larger areas in all three units of measurements. They have the highest average for neighborhood, municipality, and local labor market. The average employment rates in the local labor markets where the different ethnic groups are located are equal. If we look at the additional statistics in the Appendix Table 8, we observe that although the averages are the same, the standard deviations differ 
Table 3 Descriptive statistics: averages for the four ethnic groups

\begin{tabular}{|c|c|c|c|c|}
\hline Variable & Natives & EU $15+$ Nordic & Balkan & Middle East \\
\hline Employed & 0.80 & 0.64 & 0.70 & 0.48 \\
\hline Entrepreneur & 0.08 & 0.06 & 0.02 & 0.09 \\
\hline Age & 42.81 & 47.73 & 39.41 & 38.46 \\
\hline Male & 0.51 & 0.48 & 0.50 & 0.54 \\
\hline Education & 11.51 & 10.55 & 10.71 & 10.29 \\
\hline Time in Sweden & - & 25.90 & 10.48 & 10.29 \\
\hline Neighborhood size & 1985 & 2249 & 2066 & 2867 \\
\hline Municipality size & 119,259 & 141,500 & 147,686 & 211,406 \\
\hline Local labor market size & 686,397 & 857,983 & 631,648 & $1,046,187$ \\
\hline Employment rate in the local labor market & 0.84 & 0.84 & 0.84 & 0.84 \\
\hline Share of ethnic group in neighborhood & 0.88 & 0.07 & 0.04 & 0.13 \\
\hline Share of ethnic group in municipality & 0.86 & 0.06 & 0.01 & 0.05 \\
\hline Share of ethnic group in local labor market & 0.86 & 0.06 & 0.01 & 0.03 \\
\hline Segregation 1 (neighborhood vs. municipality) & - & 0.57 & 7.82 & -0.33 \\
\hline Segregation 2 (neighborhood vs. local labor market) & - & 0.26 & 2.25 & 1.81 \\
\hline Segregation 3 (municipality vs. local labor market) & - & 1.17 & 10.29 & 12.71 \\
\hline Number of obs. & $4,475,414$ & 239,570 & 43,151 & 167,266 \\
\hline
\end{tabular}

somewhat. So even though the average is the same, the location patterns are different between the groups. The average population shares for the three ethnic groups in the three locational units vary in approximate proportion to the size of the groups. When it comes to the segregation measures, the picture seems somewhat more complex. However, all the measures are rather normal. The major difference between the three groups is that the EU 15 and Nordic groups have smaller standard deviations and average values rather close to 0 . A value close to 0 indicates that the ethnic group is distributed approximately in the same way as the native population. For the Balkan group, we observe a relatively large mean for the first segregation measure. This means that if we look at the municipality level, Balkans tend to dwell in neighborhoods with relatively many people that have the same origin. Also, measure number three is relatively large so focusing on the local labor market people with Balkan origins tend to dwell in municipalities with relatively many peers. For the group originating from the Middle East only the average of the last (third), segregation measure deviates significantly from 0 . This means that focusing on the local labor market people with Middle East origins tends to reside in municipalities with relatively many peers.

\section{Empirical results}

The results from 4 sets of logit estimations are shown in Tables 4 and 5. The first set of results is for the employment outcome, and the second set relates to entrepreneurship. We are interested in how segregation and ethnic concentration relates to an immigrant's likelihood of being active in the labor market in 2005 either through employment or entrepreneurship. For the natives, the only available results are obtained from native concentration, since segregation is calculated with respect to the native population. For all other four groups, we have results from estimations both with the ethnic concentration and with the dissimilarity indices for segregation.

Before we go into the results, we need to address the issue of the different levels of geography present in our models. In our models, we have in fact no less than four levels the individual, the neighborhood, the municipality, and the regions. Also, the geographical levels are nested one into the other in a hierarchical manner. In order to find out the magnitude of the potential problem, we start by estimating unconditional models, that is, running the models taking into account the nested hierarchical structure but without including any regressors. We calculate the intra-class correlation coefficient (ICC) 


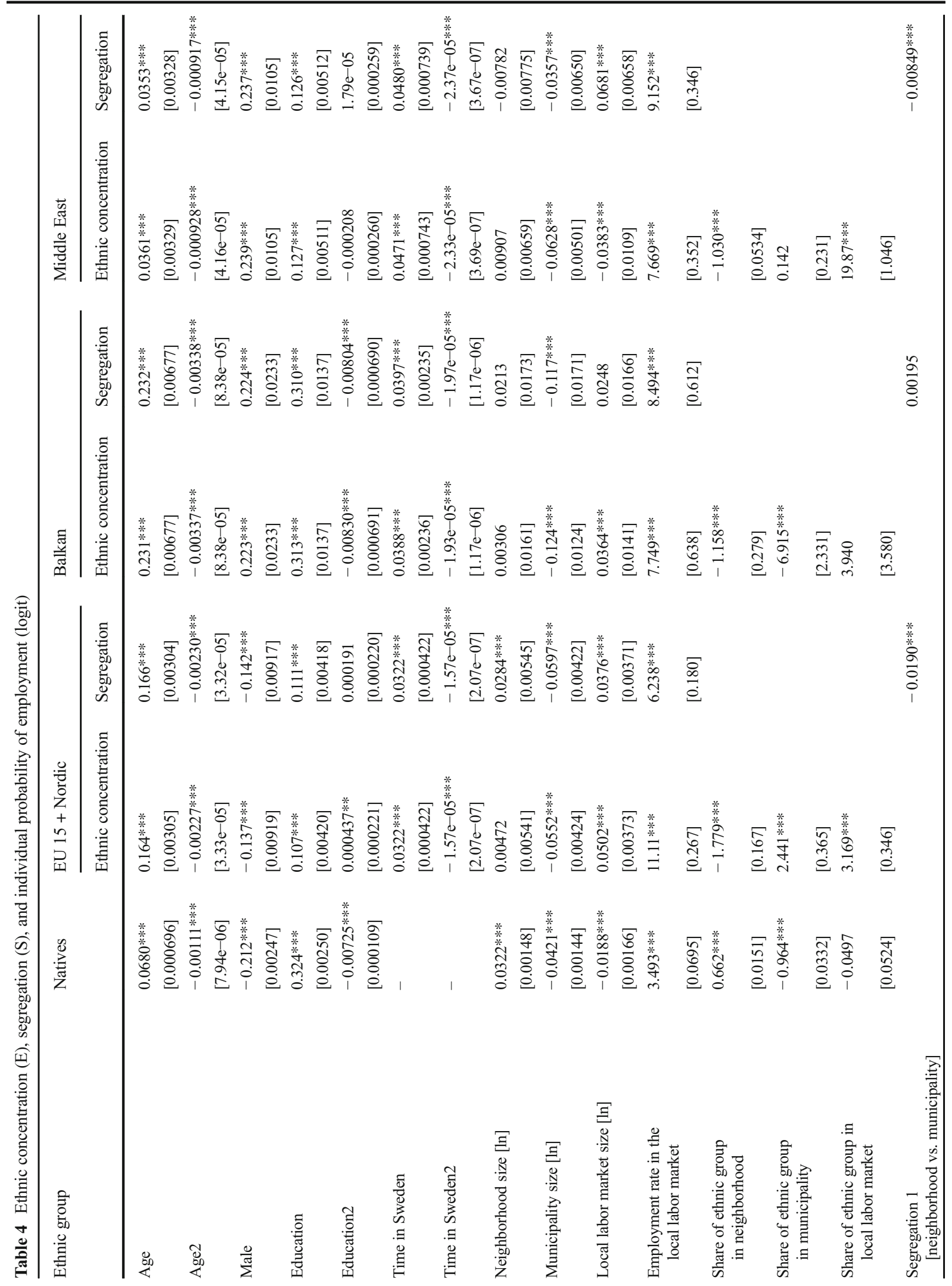




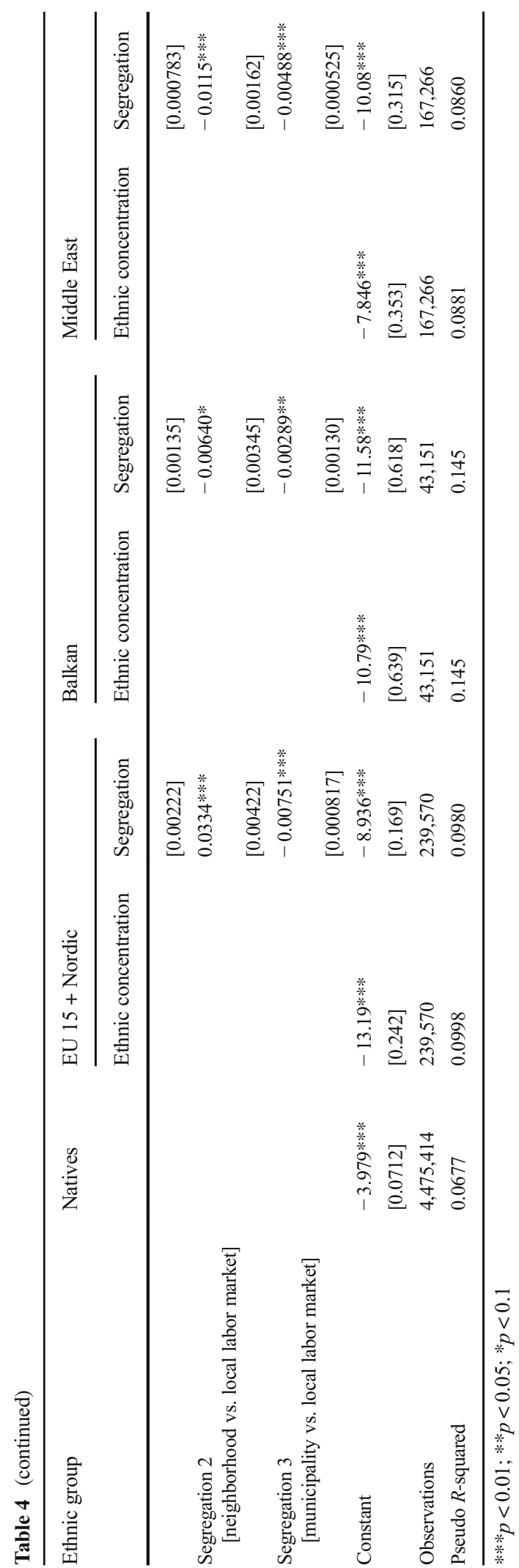

for each level and model. It turns out that the largest one is $4.6 \%$. This is a clear indication that the multilevel structure is not very important in accounting for the variation in the dependent variable. ${ }^{9}$

First, we will briefly go through the common control variables to establish the general pattern between these and our dependent variables. We do so for both the employment estimation and the entrepreneurship estimation. The first variable is age. Age is positively related to both employment and entrepreneurship probability, but at a decreasing rate. In all estimations the linear effect is positive, and the quadratic effect is negative. In terms of the size of the coefficients, they are comparable between employment and entrepreneurship. The diverging observations that can be made is that for employment probabilities the age effect is somewhat smaller for natives and very much smaller for the immigrant group coming from the Middle East.

Turning to the difference between males and females, we observe some interesting differences between the groups. The probability for males to be employed is less for males in the group of natives and immigrant from EU 15 and the Nordic countries. The opposite is true for immigrants with origins in the Balkans or the Middle East. When it comes to entrepreneurship, male immigrants have a higher probability across all four groups (including natives). The group with the largest difference between male and female is immigrants from the Middle East, where there is a much higher likelihood of being employed and being an entrepreneur for male immigrants than their female counterparts.

Education is correlated to higher probability of both employment and entrepreneurship across all groups. The quadratic term is negative for all when it comes to entrepreneurship. For employment, the picture is a little more mixed. For the three immigrant groups and for the two labor market outcomes, the time since immigration increases the probability of being employed and the probability of entrepreneurship. The effects are positive but at a decreasing rate.

\footnotetext{
${ }^{9}$ Also, as we have a very large number of observations, working with the full population rather than any sample it proves very computationally challenging to estimate multilevel models. Further, the demand for computational power is exacerbated by the fact that we have 9100 neighborhoods nested in 290 municipalities which in turn is nested in 72 regions. In the end, though, the high number of observations allows us to estimate relationships relatively precisely using the huge amount of observations. Thus, the added information by taking the level structure into account proves limited.
} 


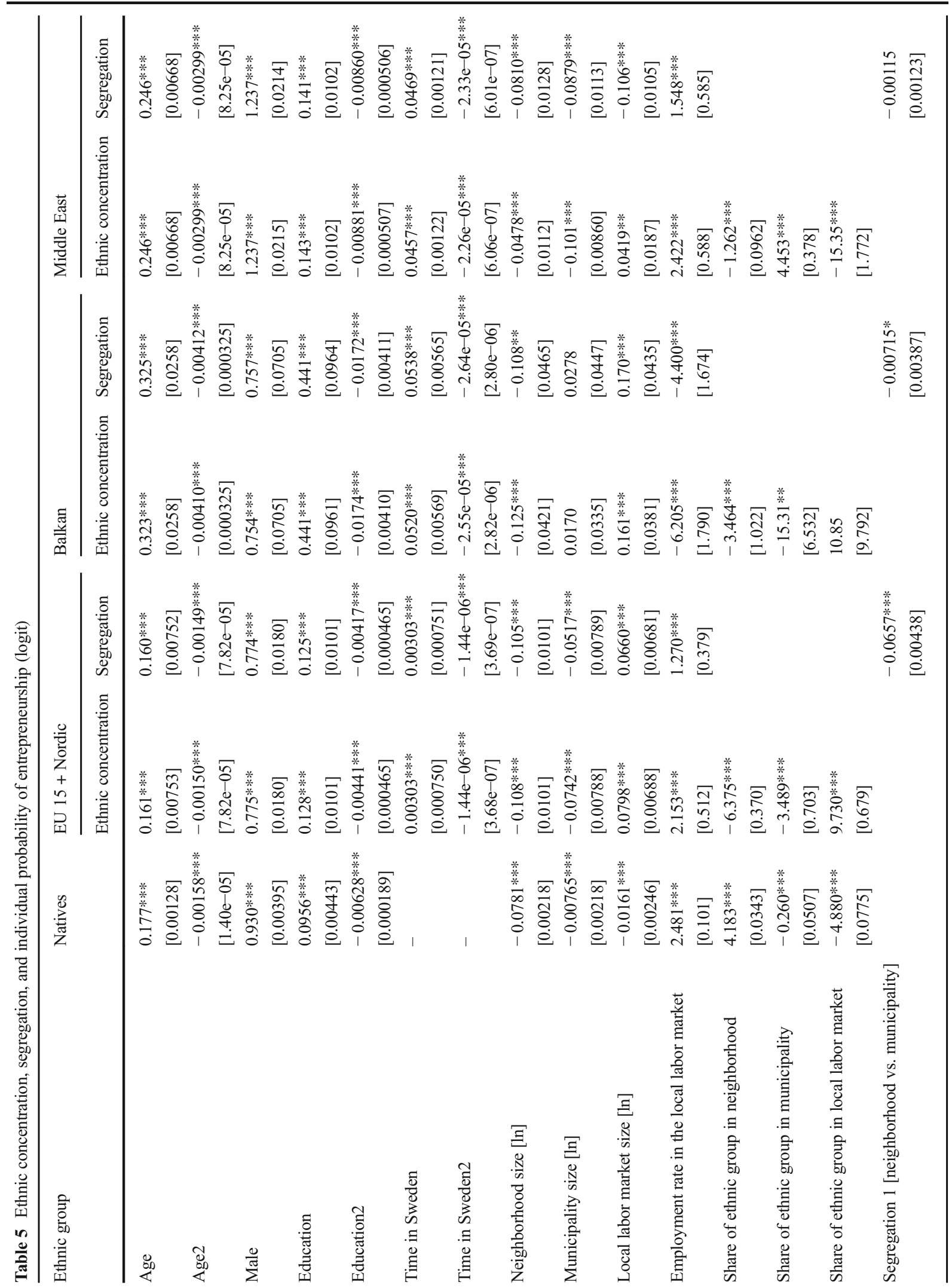




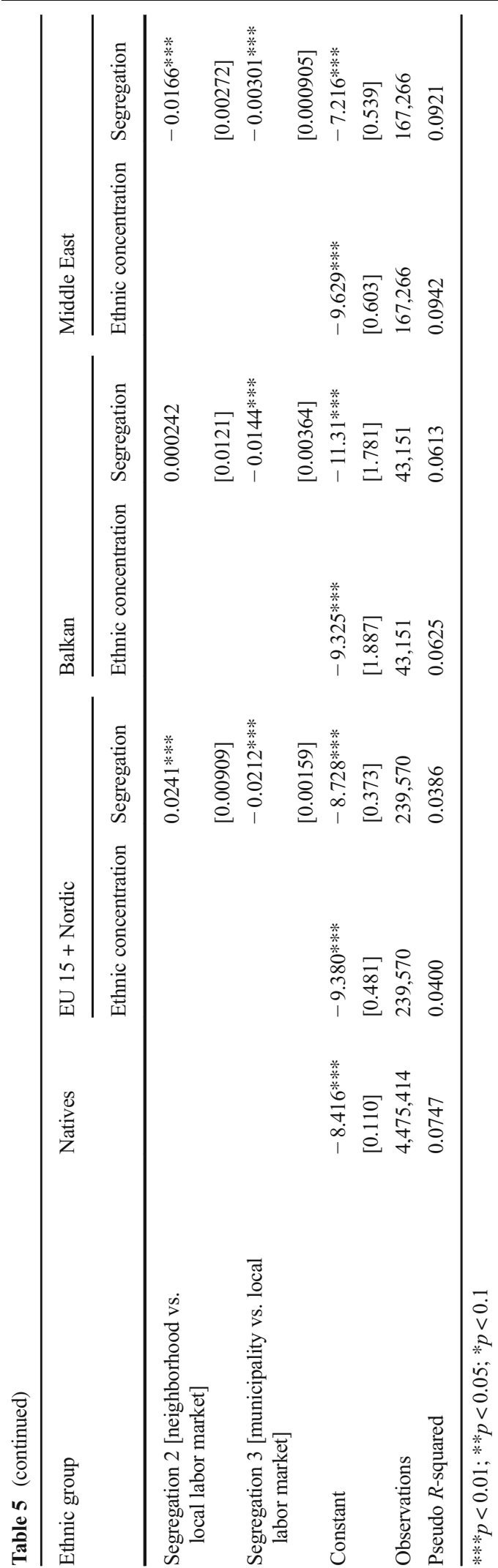

We now turn to some characteristics of the surroundings of the individuals. We look at three different levels of geography. These are neighborhood, municipality, and labor market as described above. We focus on the size of these three of regions in terms of population. In using population size, we acknowledge that these measures to a large extent work as a sort of "catch-all" variable including agglomeration effects and the urban-rural nature of the local markets. In the Swedish context, regional size correlates with many phenomena such as industry structure, wage levels, price of housing, and education levels. So, in this way, we control for many regional effects that may influence the probability that an individual finds a job or decides to start his own business.

At the neighborhood level, population size does not seem to have any clear connection to employment probabilities. At the municipality level, the picture is different; for all groups, a larger municipality size decreases the individual probability of employment. At the level of the local labor, market size seems to be bad for natives and good for immigrants from EU 15 and the Nordic countries. For the other immigrant groups, the picture is mixed. In conclusion, the overall pattern across groups and regional level can be summarized as follows: For positive employment outcomes, natives depend on the neighborhood, and immigrants from countries belonging to the EU 15 and Nordic countries depend on the local labor market. Positive correlations for the other groups can be found at the level of the local labor market, but the effects are not uniform across specifications.

Turn to the relationship between regional size and entrepreneurship probability, the relationship between neighborhood size and the probability of entrepreneurship is uniformly negative across all groups and specifications. The size effect of the municipality on individuals' entrepreneurship probability is negative for natives, immigrants from EU 15 and Nordic countries and immigrants from the Middle East. For the immigrants from the Balkans, there is no statistically significant relationship. Turning again to the size of the local labor market, we observe positive influences for immigrant's form EU 15 and Nordic countries and immigrants from the Balkans. The influence on natives is negative, and for immigrants from the Middle East, the picture is mixed.

The last of the control variables is the employment rate in the local labor market. For employment probabilities, the effect is positive for all the groups and for all 
specifications. When it comes to entrepreneurship probabilities, we find an interesting observation. The influence is positive for all groups except one. For immigrants originating from the Balkans, the effect is negative. Thus, for this group, entrepreneurship and the prospects on the labor market work as substitutes.

We now turn to our main variables of interest, ethnic concentration and ethnic segregation. Ethnic concentration at the neighborhood level is positive for natives, both for employment and entrepreneurship outcomes, whereas for all immigrant groups, ethnic concentration at the neighborhood level is negative.

At the municipality and the labor market levels, ethnic concentration is good for the employment outcomes of immigrants from the EU 15 and the Nordic countries. For immigrants from the Balkans, ethnic concentration at the municipality level is negative for the probability of employment, while at the local labor market level, it is insignificant. For immigrants from the Middle East, the probability to be employed is not statistically significantly related to ethnic concentration at the municipality level but positive at the local labor market level.

Now we turn to the relationship between employment probabilities and segregation at the various geographical levels. For immigrants from the EU 15 and the Nordic countries, the influence of segregation at the neighborhood level is negative if benchmarked against the municipality and positive if benchmarked against the labor market region. At the municipal level, segregation is negative when benchmarked against the local labor market. For the two other immigrant groups, segregation is negative (or insignificant) for employment outcomes at all geographical levels.

Concentration of natives at the municipality level is negatively related to entrepreneurship probabilities. The same is true at the local labor market level. For immigrants coming from the EU 15 or the Nordic countries, concentration at the municipal level is negatively related to entrepreneurship probability while at the local labor market level, it is positively related. For immigrants coming from the Balkans municipality, concentration is negative. There is no relationship at the local labor market level. For immigrants coming from the Middle East, there is a positive relationship between concentration and the probability of entrepreneurship at the municipality level, but a negative at the level of the local labor market.
Now we turn to segregation and the probability of entrepreneurship. For immigrants coming from the EU 15 and the Nordic countries, neighborhood segregation is negative when benchmarked against the municipality and positive when benchmarked against the local labor market region. When we look at municipality segregation relative to the local labor market, the relationship is negative. For the two other immigrant groups, segregation is negative (or insignificant) for entrepreneurship outcomes at all geographical levels.

Summing up these results to get a clearer picture, we can say:

1. Concentration of an ethnic immigrant group at the neighborhood level is negative both for the probability of employment and for the probability of entrepreneurship.

2. For immigrants from the EU 15 or the Nordic countries, effects of ethnic concentration and segregation are mixed depending on geographical level and the outcome variable.

3. For immigrants coming from the Balkans, ethnic concentration and segregation are always negatively (or insignificantly) related to the probability of employment and entrepreneurship irrespective of geographical unit of observation.

4. For immigrants from the Middle East, results are mixed when it comes to ethnic concentration effects. For segregation effects, however, the results are more uniform. Segregation is negatively (or insignificantly) related to employment and entrepreneurship outcomes at all geographical levels.

All in all, we can say that the results indicate that concentration and segregation are negatively related to the probability of having a job or owning a business, irrespective of the geographical level of measurement, for immigrants from the Balkans and the Middle East. For natives and immigrants from the EU 15 or the Nordic countries, the results are more mixed. For concentration, the neighborhood is positively related to employment and entrepreneurship probability for natives. The difference in general between natives and immigrants from the EU 15 and the Nordic countries is that the immediate neighborhood is more important for the former and the larger region is more important for the latter. 
Table 6 Ethnic concentration and migration timing and individual probability of employment and entrepreneurship (logit)

\begin{tabular}{lllll}
\hline Period & Peak & Peak & Non-peak & Non-peak \\
\hline Dependent variable & Employed & Entrepreneurship & Employed & Entrepreneurship \\
Share of ethnic group in neighborhood & $-1.145^{* * *}$ & $-3.114 * *$ & $-1.953^{* * *}$ & $-4.461^{* *}$ \\
& $(0.371)$ & $(1.216)$ & $(0.446)$ & $(1.901)$ \\
Share of ethnic group in municipality & $-9.133^{* * *}$ & $-16.17 * *$ & -1.789 & -10.19 \\
& $(3.064)$ & $(7.863)$ & $(3.737)$ & $(11.87)$ \\
Share of ethnic group in local labor market & $7.704 *$ & $(11.77)$ & -0.277 & $31.45^{*}$ \\
& $(4.627)$ & $-8.147 * * *$ & $(5.886)$ & $(17.89)$ \\
Constant & $-10.80^{* * *}$ & $(2.446)$ & $(1.031)$ & $(3.414)$ \\
& $(0.901)$ & 28,450 & 14,604 & 14,604 \\
Observations & 28,450 & 0.0561 & 0.156 & 0.0803 \\
Pseudo $R$-squared & 0.132 & & \\
\hline
\end{tabular}

The model includes all the controls present in Tables 4 and 5.

$* * * p<0.01 ; * * p<0.05 ; * p<0.1$

\subsection{Years in the country: case of Balkan migration}

One of the things that are heavily emphasized in the previous literature is the time it takes to be sorted into the labor market and how that relates to the initial timing of arrival to the receiving country. Here in this part of the analysis, in one of the groups, we have the people from Balkans that came 1993 and 1994, which were the years in which Balkan migration flow peaked. In the other groups, it is all people from Balkans regardless of their arrival time. The goal is to identify the group that clearly represents not only the forced migrants but also those who faced strong(-er) competition in the labor market because they arrived all at the same time.

Table 6 presents the results for ethnic concentration, and Table 7 presents the results for segregation. Ethnic concentration at the neighborhood level does not vary across the groups in terms of their time of arrival. But the interesting result for the ethnic concentration at the municipal level suggests that it has a negative effect for those that arrived during the peak years, both in terms of employment and in terms of entrepreneurship, whereas there is no significant relationship for the rest of the immigrant population. This result suggests a stronger

Table 7 Ethnic segregation and migration timing and individual probability of employment and entrepreneurship (logit)

\begin{tabular}{lllll}
\hline Period & Peak & Peak & Non-peak & Non-peak \\
\hline Dependent variable & Employed & Entrepreneurship & Employed & Entrepreneurship \\
Segr. 1 [neighborh. vs. mun.] & $0.00548^{* * *}$ & $-0.0112^{* *}$ & $-0.00392^{*}$ & 0.00467 \\
& $(0.00177)$ & $(0.00464)$ & $(0.00219)$ & $(0.00706)$ \\
Segr. 2 [neighborh. vs. .labor market] & $-0.0151^{* * *}$ & 0.00997 & 0.00523 & -0.0340 \\
& $(0.00432)$ & $(0.0133)$ & $(0.00587)$ & $(0.0276)$ \\
Segr. 3 [mun. vs. labor market] & -0.000985 & $-0.0142 * * *$ & $-0.00547 * *$ & $-0.0129 *$ \\
& $(0.00167)$ & $(0.00430)$ & $(0.00216)$ & $(0.00698)$ \\
Constant & $-11.67 * * *$ & $-10.91 * * *$ & $-12.31 * * *$ & $-10.84 * * *$ \\
& $(0.875)$ & $(2.293)$ & $(0.988)$ & $(3.251)$ \\
Observations & 28,450 & 28,450 & 14,604 & 14,604 \\
Pseudo $R$-squared & 0.132 & 0.0548 & 0.155 & 0.0788 \\
\hline
\end{tabular}

The model includes all the controls present in Tables 4 and 5 .

$* * * p<0.01 ; * * p<0.05 ; * p<0.1$ 
competition effect at the city level for those that arrived at the same time.

For segregation, we see a positive likelihood of employment associated with the segregation at the neighborhood level with respect to the city for those that arrive during the peak years. Such relationship is the opposite for those that arrived during other periods. When significant, segregation relates to negative outcome in all other instances.

\section{Concluding remarks}

This paper investigates the relevance of segregation as well as ethnic concentration for the labor market outcomes of immigrants in terms of employment and entrepreneurship. Our goal is empirically display notable and systematic variations across different geographical levels and across different immigrant groups. In our analysis, we differentiate between four different groups. The first group, mainly used as a benchmark, is labeled natives, consisting of people born in Sweden. The second group is people that have immigrated from the core of the EU (EU 15) plus immigrants from the Nordic countries and Switzerland. The immigrants nested under this group represent pull migration in our analysis since the migration decision is largely opportunity driven. The third group consists of immigrants that originate from the Balkans. The fourth and last group consists of people that have migrated to Sweden from the Middle East. Although we do not have an individual refugee identifier, from the national figures, we know that a vast majority of both of these groups consist of forced migrants that arrived in Sweden through asylum rights. Both the Balkan immigrants and the immigrants from the Middle East are, therefore, considered push migrants that arrived Sweden through forced migration. We study the year 2005 and argue that it is sufficiently long after the Balkan migration wave in early 1990s, and right before the peak of Middle Eastern migration wave, which provides a rather stable point in time where the enclaves are not subject to immediate and substantial changes.

We contribute to the literature in three ways. First, we argue that ethnic concentration and segregation, although they are correlated with each other, capture two different mechanisms for labor market outcomes of the immigrants. While ethnic concentration directly relates to the availability of the ethnic enclave in the surrounding area, unlike segregation measure, it does not give a comparative picture for the composition of the population in a given area with respect to a larger area. Thus, we argue, ethnic concentration relates more to the network effects while segregation captures sorting in a geography. Second, unlike a clear majority of the previous studies, we do not look at the relevance of ethnic concentration and ethnic segregation at one geographical aggregation, but rather investigate it at varying aggregations. To do that, we look at the neighborhood, municipality, and the local labor market. This is one of the very few papers that take such a multilevel approach. The reason to do so is that we argue while ethnic concentration and segregation may work in a positive (or negative way) at the neighborhood level, it may relate to different results at higher resolutions such as city (municipality) or the region (local labor market). Our results confirm that such variation is evident not only across geographical aggregations but also across different immigrant groups. Third, we do not only look at one or few metropolitan areas but also investigate the country as a whole. Although historically labor migration (pull migration) led to the formation of ethnically segregated areas in urban markets, recent trends with forced migration in Europe manifested ethnically concentrated areas to show up not only in the urban areas but also in rural areas. Thus, our analysis makes a distinction between the two and presents results for the urban and rural markets separately.

Our results show that there are large differences between the immigrant groups, especially between pull and push migrants, regardless of which specification we use. In broad strokes, concentration of an ethnic immigrant group at the neighborhood level is negative both for the probability of employment and for the probability of entrepreneurship. For immigrants from the EU 15 or the Nordic countries, effects of ethnic concentration and segregation are mixed depending on geographical level and the outcome variable. For immigrants coming from the Balkans, ethnic concentration and segregation are always negatively (or insignificantly) related to the probability of employment and entrepreneurship irrespective of geographical unit of observation. For immigrants from the Middle East, results are mixed when it comes to ethnic concentration effects. For segregation effects, however, the results are more uniform. Segregation is negatively (or insignificantly) related to employment and entrepreneurship outcomes at all geographical levels. 
Understanding the mechanisms through which ethnic enclaves and segregation operates for producing various labor market outcomes is an important quest for researchers, but equally important for policy makers. Crafting policies related to residential segregation requires careful consideration of geography, as different geographical aggregations relate to different outcomes. We find that ethnic enclaves, proxied by ethnic concentration at varying levels, indicate mixed results for the different immigrant groups we study, both for their employment and entrepreneurship probability, whereas residential segregation has a more uniformly distributed result where its relationship to any of the two labor market outcomes is almost always negative or insignificant. This result is consistent across immigrant groups and across different specifications. Our research is not able to draw causal inference on specific mechanisms through which ethnic concentration and segregation affect labor market outcomes for immigrants, but rather display empirically the importance of spatial aggregation, which is something the literature has been silent about. Further research can build on this premise and focus more on spatial dimension in their empirical set up while addressing issues of causality where there is room for improvement. We conclude by saying that while ethnic networks may ease labor market integration of immigrants, residential segregation itself-being a measure of dissimilarity in an area-yields undesirable labor market outcomes.

\section{Appendix}

Table 8 Descriptive statistics by the immigrant groups

\begin{tabular}{|c|c|c|c|c|c|c|c|c|}
\hline & \multicolumn{2}{|l|}{ Natives } & \multicolumn{2}{|c|}{ EU 15 + Nordic } & \multicolumn{2}{|l|}{ Balkan } & \multicolumn{2}{|c|}{ Middle East } \\
\hline & Mean & S. Dev. & Mean & S. Dev. & Mean & S. Dev. & Mean & S. Dev. \\
\hline Employed & 0.80 & 0.40 & 0.64 & 0.48 & 0.70 & 0.46 & 0.48 & 0.50 \\
\hline Entrepreneur & 0.08 & 0.27 & 0.06 & 0.24 & 0.02 & 0.15 & 0.09 & 0.28 \\
\hline Age & 42.81 & 13.04 & 47.73 & 11.69 & 39.41 & 11.82 & 38.46 & 11.03 \\
\hline Male & 0.51 & 0.50 & 0.48 & 0.50 & 0.50 & 0.50 & 0.54 & 0.50 \\
\hline Education & 11.51 & 2.58 & 10.55 & 3.78 & 10.71 & 3.20 & 10.29 & 3.87 \\
\hline Time in Sweden & - & - & 25.90 & 151.53 & 10.48 & 5.23 & 13.06 & 8.21 \\
\hline Neighborhood size & 1985 & 2374 & 2249 & 2619 & 2066 & 1898 & 2867 & 2651 \\
\hline Municipality size & 119,259 & 182,323 & 141,500 & 204,119 & 147,686 & 169,228 & 211,406 & 221,491 \\
\hline Local labor market size & 686,397 & 687,102 & 857,983 & 738,486 & 631,648 & 552,047 & $1,046,187$ & 702,360 \\
\hline Employment rate in the local labor market & 0.84 & 0.02 & 0.84 & 0.03 & 0.84 & 0.02 & 0.84 & 0.02 \\
\hline Share of ethnic group in neighborhood & 0.88 & 0.10 & 0.07 & 0.06 & 0.04 & 0.05 & 0.13 & 0.12 \\
\hline Share of ethnic group in municipality & 0.86 & 0.07 & 0.06 & 0.05 & 0.01 & 0.01 & 0.05 & 0.03 \\
\hline Share of ethnic group in local labor market & 0.86 & 0.05 & 0.06 & 0.05 & 0.01 & 0.01 & 0.03 & 0.01 \\
\hline Segregation 1 (neighborhood vs. municipality) & - & - & 0.57 & 2.66 & 7.82 & 12.45 & -0.33 & 7.06 \\
\hline Segregation 2 (neighborhood vs. local labor market) & - & - & 0.26 & 1.50 & 2.25 & 4.70 & 1.81 & 4.01 \\
\hline Segregation 3 (municipality vs. local labor market) & - & - & 1.17 & 5.95 & 10.29 & 12.92 & 12.71 & 14.53 \\
\hline Observations & \multicolumn{2}{|c|}{$4,475,414$} & \multicolumn{2}{|l|}{239,570} & \multicolumn{2}{|l|}{43,151} & \multicolumn{2}{|l|}{167,266} \\
\hline
\end{tabular}


Open Access This article is licensed under a Creative Commons Attribution 4.0 International License, which permits use, sharing, adaptation, distribution and reproduction in any medium or format, as long as you give appropriate credit to the original author(s) and the source, provide a link to the Creative Commons licence, and indicate if changes were made. The images or other third party material in this article are included in the article's Creative Commons licence, unless indicated otherwise in a credit line to the material. If material is not included in the article's Creative Commons licence and your intended use is not permitted by statutory regulation or exceeds the permitted use, you will need to obtain permission directly from the copyright holder. To view a copy of this licence, visit http://creativecommons.org/licenses/by/4.0/.

\section{References}

Andersson, F., Burgess, S. M., \& Lane, J. (2009). Do as the neighbors do: The impact of social networks on immigrant employment, IZA discussion paper no. 4423.

Andersson, H. (2017). Ethnic enclaves, self-employment and the economic performance of refugees, (job market paper), online available: https://sites.google.com/view/henrikandersson/research

Andersson, H., Berg, H. \& Dahlberg, M. (2016a). Migrating natives and foreign immigration (Presented at European Regional Science Association's Annual Meeting in Vienna).

Andersson, M, Larsson, J.P., Öner, Ö. (2017). Ethnic enclaves and immigrant self-employment: a neighborhood analysis of enclave size and quality, IFN Working Paper Series, no.1195.

Andersson, M., \& Larsson, J. P. (2014). Local entrepreneurship clusters in cities. Journal of Economic Geography, 16(1), 3966.

Andersson, M., Klaesson, J., \& Larsson, J. P. (2016b). How local are spatial density externalities? - neighborhood effects in agglomeration economies. Regional Studies, 50(6), 10821095. https://doi.org/10.1080/00343404.2014.968119.

Arai, M., \& Skogman Thoursie, P. (2009). Renouncing personal names: an empirical examination of surname change and earnings. Journal of Labor Economics, 27(1), 127-147.

Arzaghi, M., \& Henderson, J. V. (2008). Networking off Madison avenue. The Review of Economic Studies, 75(4), 1011-1038.

Bayer, P., Ross, S., \& Topa, G. (2008). Place of work and place of residence: informal hiring networks and labor market outcomes. Journal of Political Economy, 116(6), 1150-1196.

Beaman, L. A. (2012). Social networks and the dynamics of labour market outcomes: evidence from refugees resettled in the US. The Review of Economic Studies, 79(1), 128-161.

Borjas, G. J. (1995). Ethnicity, neighborhoods, and human capital externalities. American Economic Review, 85, 365-390.

Borjas, G. J. (1998). To ghetto or not to ghetto: ethnicity and residential segregation. Journal of Urban Economics, 44(2), $228-253$.

Borjas, G. J. (2000). Ethnic enclaves and assimilation. Swedish Economic policy review, 7(2), 89-122.

Carlsson, M., \& Rooth, D. O. (2007). Evidence of ethnic discrimination in the Swedish labor market using experimental data. Labour Economics, 14(4), 716-729.
Clark, K., \& Drinkwater, S. (2000). Pushed out or pulled in? Selfemployment among ethnic minorities in England and Wales. Labour Economics, 7(5), 603-628.

Clark, K., \& Drinkwater, S. (2002). Enclaves, neighbourhood effects and economic activity: ethnic minorities in England and Wales. Journal of Population Economics, 15, 5-30.

Clark, K., \& Drinkwater, S. (2010). Patterns of ethnic selfemployment in time and space: evidence from British census microdata. Small Business Economics, 34(3), 323-338.

Collins, J., \& Low, A. (2010). Asian female immigrant entrepreneurs in small and medium-sized businesses in Australia. Entrepreneurship and Regional Development, 22(1), 97-111.

Cutler, D. M., Glaeser, E. L., \& Vigdor, J. L. (2008). When are ghettos bad? Lessons from immigrant segregation in the United States. Journal of Urban Economics, 63(3), 759-774.

Edin, P.-A., Fredriksson, P., \& Åslund, O. (2003). Ethnic enclaves and the economic success of immigrants: evidence from a natural experiment. The Quarterly Journal of Economics, $118(1), 329-357$.

Glaeser, E. L., H. Vernon, and R. P. Inman (2000). The future of urban research: nonmarket interactions. Brookings-Wharton Papers on Urban Affairs, 101-149.

Granovetter, M. (1995). Getting a job: a study of contacts and careers. Chicago: University of Chicago Press.

Granovetter, M. S. (1973). The strength of weak ties. American Journal of Sociology, 78(6), 1360-1380.

Hedberg, C., \& Tammaru, T. (2013). 'Neighbourhood effects' and 'city effects': the entry of newly arrived immigrants into the labour market. Urban Studies, 50(6), 1165-1182.

Hensvik, L., and O. Nordström Skans (2013). Social networks, employee selection and labor market outcomes. IFAU Institute for Evaluation of Labour Market and Education Policy.

Hout, M., \& Rosen, H. (2000). Self-employment, family background, and race. Journal of Human Resources, 35, 670-692.

Jean, S., Causa, O., Jiménez, M., \& Wanner, I. (2010). Migration and labour market outcomes in OECD countries. OECD Journal. Economic Studies, 2010(1), 1.

Kloosterman, R., \& Rath, J. (2001). Immigrant entrepreneurs in advanced economies: mixed embeddedness further explored. Journal of Ethnic and Migration Studies, 27(2), 189-201.

Knack, S., \& Keefer, P. (1997). Does social capital have an economic payoff? A cross-country investigation. The Quarterly Journal of Economics, 1251-1288.

Larsson, J. P. (2014a). Nonmarket interactions and density externalities. PhD Thesis: 96, Jönköping International Business School: Jönköping.

Larsson, J. P. (2014b). The neighborhood or the region? Reassessing the density-wage relationship using geocoded data. The Annals of Regional Science, 52(2), 367-384.

Lassmann, A., \& Busch, C. (2015). Revisiting native and immigrant entrepreneurial activity. Small Business Economics, 45(4), 841-873.

Lee, A. T. (2000). The determinants of immigrant selfemployment in Australia. International Migration Review, 183-214.

Levie, J. (2007). Immigration, in-migration, ethnicity and entrepreneurship in the United Kingdom. Small Business Economics, 28(2), 143-169.

Lofstrom, M., \& Lofstrom, M. (2014). Immigrants and entrepreneurship. IZA World of Labor, 14, 1-10. 
Manski, C. F. (1993). Identification of endogenous social effects: the reflection problem. The Review of Economic Studies, 60(3), 531-542.

Nannestad, P. (2009). Unproductive immigrants: a socially optimal policy for rational egalitarians. European Journal of Political Economy, 25(4), 562-566.

OECD. (2006). From immigration to integration: local solutions to a global challenge. OECD policy brief, 2006.

Parker, S. C. (2009). The economics of entrepreneurship. Cambridge: Cambridge University Press.

Patacchini, E., \& Zenou, Y. (2012). Ethnic networks and employment outcomes. Regional Science and Urban Economics, 42(6), 938-949.

Peroni, C., Riillo, C. A., \& Sarracino, F. (2016). Entrepreneurship and immigration: evidence from GEM Luxembourg. Small Business Economics, 46(4), 639-656.

Rosenthal, S. S., \& Strange, W. C. (2008). The attenuation of human capital spillovers. Journal of Urban Economics, 64(2), 373-389. https://doi.org/10.1016/j.jue.2008.02.006.
Topa, G. (2001). Social interactions, local spillovers and unemployment. The Review of Economic Studies, 68(2), 261-295.

Walstad, W. B., \& Kourilsky, M. L. (1998). Entrepreneurial attitudes and knowledge of black youth. Entrepreneurship Theory and Practice, 23, 5-18.

Warman, C. (2007). Ethnic enclaves and immigrant earnings growth. Canadian Journal of Economics/Revue canadienne d'économique, 40(2), 401-422.

Zenou, Y. (2007). Social interactions and labour market outcomes in cities. IFN Working Paper, No. 755.

Publisher's note Springer Nature remains neutral with regard to jurisdictional claims in published maps and institutional affiliations. 